\title{
Foundation Adaptability and Subgrade Deformation Analysis of High-Speed Railway above the Mined-Out Areas
}

\author{
Shuren Wang ${ }^{1,2^{*}}$, Kunpeng Shi ${ }^{1}$, Tonghe Zhou ${ }^{1}$, Youfeng Zou ${ }^{1}$ and Jiangchun $\mathrm{Hu}^{1}$ \\ ${ }^{1}$ International Joint Research Laboratory of Henan Province for Underground Space Development and Disaster Prevention, \\ Henan Polytechnic University, Jiaozuo 454003, China \\ ${ }^{2}$ School of Minerals and Energy Resources Engineering, University of New South Wales, Sydney, NSW 2052, Australia
}

Received 7 October 2020; Accepted 25 December 2020

\begin{abstract}
To ensure the operation safety of the high-speed railway above the mined-out areas, the new evaluation standard suitable for the foundation adaptability in the mined-out areas was proposed based on the conventional judgment standard $\left(\sigma_{\mathrm{z}}=0.10 \sigma_{\mathrm{cz}}\right)$ by combining theoretical analysis with numerical simulation. According to Winkler's elastic foundation beam theory, the analytical model was built to analyze the relationship between the subgrade deformation and foundation settlement in the mined-out areas. The calculation formula of the subgrade deflection was derived and the inclination coefficient of the subgrade was introduced to explore the influences of different foundation settlements on the subgrade geometry. The influence of amplitude and wavelength of foundation settlement on the subgrade deformation was analyzed. Results show that the pattern of the subgrade deflection basically remains unchanged when the uneven settlement of a cosine-type ground is transferred to the subgrade. The settlement and inclination of the subgrade are controlled by the wavelength and amplitude of uneven settlement. The subgrade settlement gradually decreases with the increase of the amplitude of foundation settlement. When the wavelength is more than $50 \mathrm{~m}$, the subgrade settlement gradually tends to be stable. When the half wave length of foundation settlement is equal to the width of the subgrade, the inclination of the subgrade is the largest. The proposed empirical equations that used to further describe the subgrade settlement and slope coefficient with variation of the amplitude and wavelength of the foundation settlement can be applied to predict the geometric mapping relationship between the uneven foundation settlement and the subgrade deformation in the mined-out areas.
\end{abstract}

Keywords: Mined-out area, Suitability evaluation, Winkler foundation beam, Subgrade deformation

\section{Introduction}

With the increasing of construction density of the high-speed railway network, the available land resources are declining in China. Some high-speed railways have to cross the mined-out areas, and the infrastructure construction above the mined-out areas has become an inevitable trend. However, the research on the deformation control of the foundation and subgrade of the high-speed railway above the mined-out areas is still a relatively new topic in the world.

At present, there are various methods for determining the foundation adaptability above the mined-out areas, but there is little reported about the uniform and accurate criterion. In addition, most scholars focused on the influence of the upper dynamic and static loads on the subgrade deformation of high-speed railway, and there is still a lack of research considering the foundation adaptability of the high-speed railway and the uneven settlement of the foundation above the mined-out areas. During the train long-term operation, the foundation will continue to suffer from the impact of the train vibration loading, which leads to the decrease of the durability of the mined-out areas.

The subsidence of the mined-out areas has a significant impact on the stability of the ground infrastructure [1-3]. At the same time, under the action of the cyclic dynamic load of

*E-mail address: shurenwang@hpu.edu.cn

ISSN: 1791-2377 @ 2021 School of Science, IHU. All rights reserved. doi:10.25103/jestr.141.20 the high-speed railway and the weight of the track system, the additional stress may break the relative balance of the damaged overburden rock and reactivate the mined-out areas, which will lead to the catastrophic damage such as uneven settlement, inclination, and collapse of the foundation. These potential risks seriously affect the planning and construction of the high-speed railway above the mined-out areas, as well as the operation safety of the high-speed railway [5-8]. Therefore, it is of great significance to study the foundation deformation above the mined-out areas, thus ensure the operation safety of the high-speed railway.

\section{State of the Art}

The foundation adaptability of high-speed railway above the mined-out area is the key to ensure the operation safety of high-speed railway. The foundation stability above the mined-out areas is closely related to the buried depth, mining height, and location distribution of the mined-out areas [9]. Most scholars think that the additional stress generated by the building load in the foundation is equal to $10 \%$ or $20 \%$ of the geostatic stress of the foundation at the corresponding depth, that is, the influence of the surface building load on the foundation at this depth can be ignored, which can be used as the criterion to judge the adaptability of the building foundation [10]. Based on this criterion, Ren et al. proposed a simple reference standard for the suitability 
evaluation of the building foundation above the mined-out areas [11]. Diaz-Fernandez et al. established a settlement prediction model suitable for predicting the project passing through the mined-out areas on the basis of the parameter modification of the probability integral model 00 . Guo et al . put forward the criterion of full mining degree of the overburden rock failure and its height calculation method [12]. Xu et al. studied the deformation characteristics of the building foundation in the caved zone by analyzing the distribution of additional stress and residual voids in the fractured zone in the mined-out areas [13]. $\mathrm{Ng}$ et al. predicted the surface subsidence of the mined-out areas based on the synthetic aperture radar interferometry technology [14-15].

It is crucial to ensure the safety of the high-speed railway even a small amount of line deformation in the operation. There are some potential factors for additional settlement, such as geological characteristics, embankment height, frozen soil compaction, and the train dynamic load [16]. The unevenness of the foundation stiffness and the transition zone between the soft soil and the rigid structure will cause uneven settlement of the rail [17]. There are various foundation models such as Winkler, Pasternak, Vlasov and either Euler-Bernoulli or Timoshenko beams being widely used [18-19]. In the case of uniform linear foundation, the increase of foundation stiffness leads to the decrease of peak displacement and higher critical velocity. For the nonlinear foundation, the increase of load strength will lead to higher displacement and higher critical velocity [20]. Khan et al. proposed a model that used Winkler's elastic foundation theory to analyze the subgrade and they estimated the extreme expansion and contraction displacement of the expansive foundation soil [21]. Neto et al. studied the surface settlement of geogrid-reinforced soil and the propagation of vertical stress based on the theory of doublelayer foundation beams [22-24].

Guo et al. proposed a new iterative method and studied the mapping characteristics of the deflection profile in the ballastless track-subgrade system [25-27]. Zhang et al. determined the dynamic response and cumulative settlement characteristics of the subgrade and they evaluated the subgrade adaptability on the high-speed railways [28]. All the above mentioned literatures focused on the deflection of the subgrade under traffic load through the elastic foundation beam theory, but not considering the differential settlement to study the characteristics of the inclined deformation of the subgrade.

Taking Taijiao high-speed railway above the Xincheng mined-out areas in Changzhi city, Shanxi province, China, as the engineering background, the criterion of the foundation suitability of the high-speed railway above the mined-out areas was studied. According to Winkler's elastic foundation beam theory, the theoretical model of foundation beam with symmetric and asymmetric displacement boundary conditions was established and the calculation method of the foundation settlement for the high-speed railway was derived. Then the geometric mapping relationship of the subgrade deformation to the settlement amplitude and wavelength was analyzed, which could provide the theoretical basis and technical support for the high-speed railway passing through the mined-out areas.

The rest of this study is organized as follows. Section 3 describes the relevant background and the research methods. Section 4 gives the results and discussion, and finally, the conclusions are summarized in Section 5.

\section{Methodology}

\subsection{Engineering background}

Taijiao high-speed railway is an important part of the national 13th Five-Year Plan key construction project. It is designed for passenger with a speed of $250 \mathrm{~km} / \mathrm{h}$. The line starts from Taiyuan south station in the north, followed by 10 stations, then introduces Jiaozuo station, with a total length of about $360 \mathrm{~km}$. According to the location relationship, the Taijiao high-speed railway must pass through the Qinshui coal field to introduce Changzhi and Jincheng cities, while the Changzhi-Xincheng mined-out areas are the only way to introduce Gaoping and Jincheng cities through the Qinshui coal field [29]. This section is located at the intersection of Jinhuo and Zhuangtou fault zones. The distribution of mined-out areas along Taijiao high-speed railway is shown in Fig. 1. There are a large number of shallow mined-out areas, the average buried depth is $146 \mathrm{~m}$, and the minimum buried depth is $103 \mathrm{~m}$. The geological section of the typical mined-out areas is shown in Fig. 2.

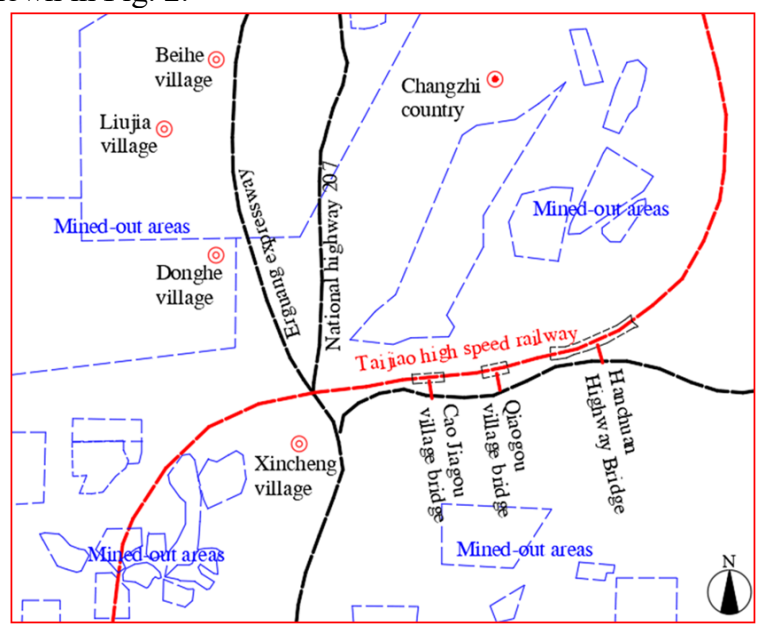

Fig. 1. The distribution of mined-out areas along Taijiao high-speed railway.

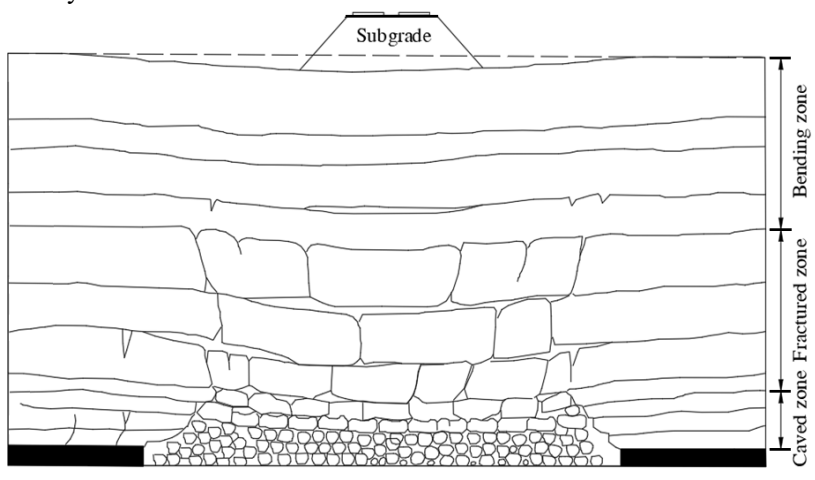

Fig. 2. Geological section of the typical mined-out areas.

3.2 Foundation suitability of high-speed railway above the mined-out areas

For the special geotechnical engineering of the foundation above the mined-out areas, before the coal being mined, the foundation's self-weight stress increases linearly with the depth, but after mining, the foundation's stress above the mined-out areas has undergone the complex changes. The traditional calculation method of the additional stress in the general foundation is roughly used $\sigma_{\mathrm{z}}=0.10 \sigma_{\mathrm{cz}}, \sigma_{\mathrm{z}}=0.20 \sigma_{\mathrm{cz}}$ as the basis for judging the depth of the influence of the additional load, which is inappropriate for the foundation above the mined-out areas.

The computational model with a length of $400 \mathrm{~m}$ and a depth of $150 \mathrm{~m}$ was established by using the finite element 
method. The minimum buried depth of the coal seam was $103 \mathrm{~m}$, the coal was $3 \mathrm{~m}$ thick, and the topsoil was $35 \mathrm{~m}$ thick. The rocks were hard lithology, such as mudstone and sandstone. The subgrade was simplified as the uniformly distributed load, and $20 \mathrm{kPa}$ was considered for every $1 \mathrm{~m}$ high subgrade load. The conditions of different load sizes on the surface before and after mining were simulated. The additional stress in the foundation before and after coal mining was simulated by using different physical and mechanical parameters of rock mass. The calculation results under different determination criteria and numerical simulation results are shown in Figs. 3 and 4 [11].

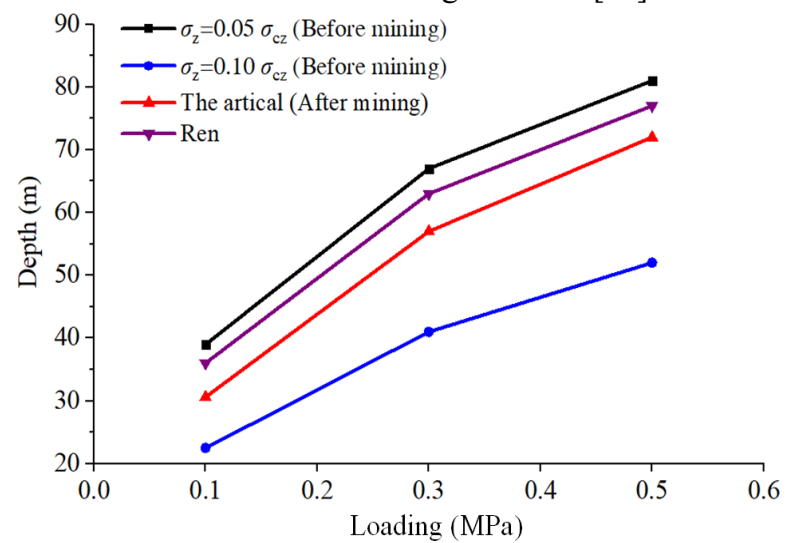

Fig. 3 Influence depth under different loadings.

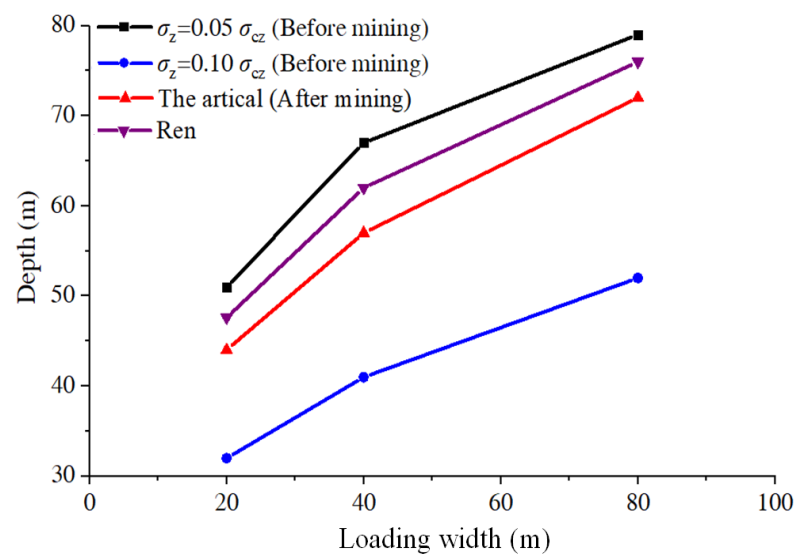

Fig. 4 Influence depth under different loading widths.

As seen from Figs. 3 and 4, the influence depth of the additional stress increases nonlinearly with increase of the loading and loading width. According to the different criteria, the influence depth of the additional stress is also different. Before coal mining, the influence depth of the additional stress is $H_{1}\left(\sigma_{\mathrm{z}}=0.05 \sigma_{\mathrm{cz}}\right)>H_{3}($ Ren $)>$ $H_{2}\left(\sigma_{\mathrm{z}}=0.10 \sigma_{\mathrm{cz}}\right)$. There is a big error between the actual influence depth of the additional stress after coal mining and these three discriminant results. $H_{1}$ is generally larger than the actual influence depth of the additional stress. $\mathrm{H}_{2}$ is generally smaller than the actual influence depth of the additional stress. and $\mathrm{H}_{3}$ has a smaller error value compared with $H_{1}$ and $H_{2}$. But there is still an error of more than $10 \%$ between $\mathrm{H}_{3}$ and the actual influence depth of the additional stress.

According to the discriminant standard of $\sigma_{\mathrm{z}}=0.10 \sigma_{\mathrm{cz}}$ before mining, the magnification coefficient of the load influence depth is introduced,

$\delta=\frac{H_{\mathrm{z}}}{H_{\mathrm{cz}}}$ where, $H_{\mathrm{z}}$ is the influence depth of the additional stress. $\delta$ is the amplification factor of the influence depth of the additional stress, and $H_{\mathrm{cz}}$ is the load influence depth of $\sigma_{\mathrm{z}}=0.10 \sigma_{\mathrm{cz}}$ criterion.

Comparing the actual impact depth $H_{\mathrm{z}}$ of the loading obtained by the numerical analysis with $H_{\mathrm{cz}}$, the magnification coefficient $\delta$ of the impact depth of the loading is obtained, as shown in Table 1. It can be seen from Table 1, the $\delta$ fluctuates between 1.3 and 1.5. Under the same loading conditons, the greater the $\delta$ value, the greater the influence depth of the additional stress. For the minedout areas, the amplification factor $\delta$ of the influence depth can be appropriately increased to ensure the construction and operation safety of the high-speed railway engineering.

Table 1. The magnification coefficient of influence depth under different loading conditions.

\begin{tabular}{|c|c|c|c|}
\hline Loading (MPa) & 0.1 & 0.3 & 0.5 \\
\hline Magnification coefficient $\delta$ & 1.36 & 1.39 & 1.38 \\
\hline Loading width (m) & 20 & 40 & 80 \\
\hline Magnification coefficient $\delta$ & 1.37 & 1.44 & 1.38 \\
\hline
\end{tabular}

In general, after the coal being mined, the overlying rock layer forms the caved zone, fractured zone, and bending zone from bottom to top. The height of the caved and the fractured zones are mainly related to the coal mining thickness, dip angle, mining size, overlying rock lithology, roof management method and other factors. In general, the height of the caved zone is 3-5 times of the coal mining thickness, and the height of the fractured zone is 9-35 times of coal mining thickness. According to the investigation results and relevant specifications, the calculation formula for the height of the caved zone $H_{\mathrm{m}}$ and the height of the fractured zone $H_{\mathrm{li}}$ is as follows, respectively:

$$
\begin{aligned}
& H_{\mathrm{m}}=\frac{100 \sum M}{2.1 \sum M+16}+2.5 \\
& H_{\mathrm{li}}=30 \sqrt{\sum M}+10
\end{aligned}
$$

where, $\sum M$ is the cumulative mining thickness of the coal seam.

The determination height is based on whether the maximum influence depth of the loading reaches the range of the fractured zone in the mined-out area, that is, the minimum mining depth of the coal seam should be greater than the sum of the maximum influence depth of loading, the height of the caved zone and fractured zone,

$$
H_{\min }>H_{\mathrm{z}}+H_{\mathrm{m}}+H_{\mathrm{li}}
$$

where, $H_{\min }$ is the minimum mining depth of coal seam. $H_{\mathrm{z}}$ is the maximum influence depth of loading. $H_{\mathrm{m}}$ is the height of the caved zone, and $H_{\mathrm{li}}$ is the height of the fractured zone. It can be seen from Eq. (4) that the greater the buried depth of the mined-out areas, the smaller the possibility of secondary activation of the mined-out areas caused by the additional stress.

According to Subgrade and Track Engineering of Highspeed Railway in China, the height of subgrade is generally 3-4 $\mathrm{m}$. This study expands the research scope to $2-5 \mathrm{~m}$ and takes Xincheng mined-out areas as the engineering background. As the high-speed railway subgrade 
engineering belongs to infrastructure with high safety level and which above the mined-out areas, 1.44 is selected as the amplification factor in this study. Through Eqs. (2) and (3), the maximum influence depth of loading on different subgrade heights and the minimum mining depth of coal seam without "secondary activation" were calculated as shown in Fig. 5. The dotted line in Fig. 5 is the minimum buried depth of the mined-out areas along the Taijiao highspeed railway. The height of the subgrade is less than $3 \mathrm{~m}$, which satisfies the criterion of Eq. (4), and there is no secondary activation in the mined-out area. When the height of the subgrade is greater than $3 \mathrm{~m}$, the influence depth of loading reaches the fractured zone of the mined-out areas, that is, $H_{\min }<H_{\mathrm{z}}+H_{\mathrm{m}}+H_{\mathrm{li}}$, which can lead to further compaction of the fractured zone and the potential risk of secondary activation of the mined-out areas.

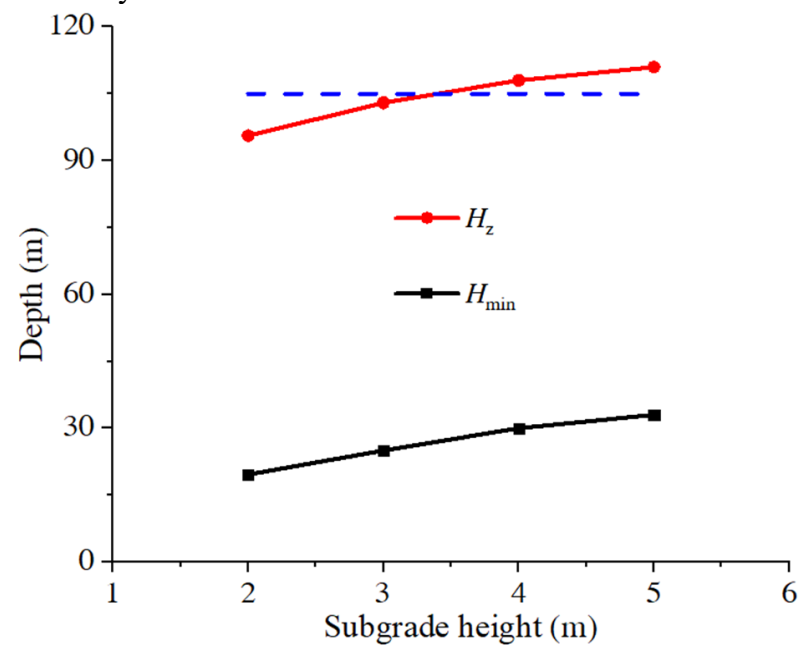

Fig. 5 The maximum influence depth of loading with different subgrade heights.

\subsection{Subgrade settlement based on foundation beam theory}

As shown in Fig. 6, when studying the influence of uneven settlement of the subgrade on track structure, the half-wave sinusoidal curve was usually adopted in Japan, while the concave full-wave cosine curve was mostly used in China [30].

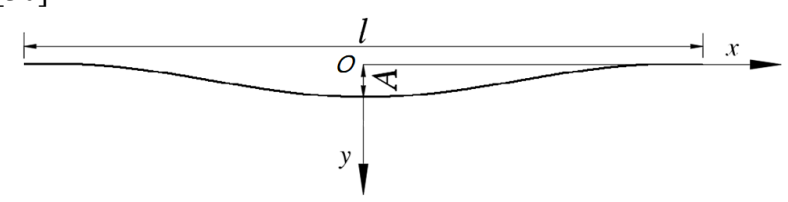

Fig. 6 The concave full-wave cosine curve.

In this study, the concave cosine curve is also used to simulate the non-uniform settlement of the foundation, and its description function is:

$$
f(x)=\frac{A}{2}\left(1-\cos \frac{2 \pi}{l}\right)
$$

where, $x$ is the coordinate of a certain point along the longitudinal direction of the line. $A$ is the settlement amplitude, and $l$ is the settlement wavelength.

The longitudinal section of the subgrade is selected to analyze the subgrade settlement, and the subgrade section is simplified as rectangular beam. The foundation beam model of the subgrade is established as shown in Fig. 7. According to the basic deflection differential equation, the foundation beam can be obtained:
$\mathrm{EI} \frac{d^{4} w}{d w^{4}}+k w=\gamma h+k f(x)$

where, EI is the stiffness of the foundation beam. $w$ is the deflection of the beam. $k$ is the foundation reaction coefficient.

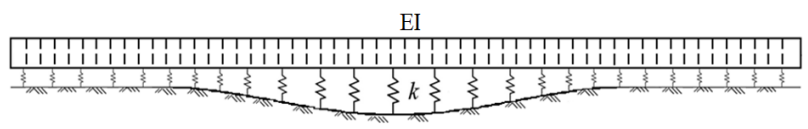

Fig. 7 The infinite beam model of uneven settlement subgrade.

According to the symmetry of the subsiding curve, only the deformation of the right half of the subsiding curve is considered, then Eq. (7) can be written:

$$
\left\{\begin{array}{l}
\mathrm{EI} \frac{d^{4} w_{1}}{d x^{4}}+k w_{1}=\gamma h+k f(x), \quad 0 \leq x \leq \frac{1}{2} \\
\mathrm{EI} \frac{d^{4} w_{1}}{d x^{4}}+k w_{1}=\gamma h, \quad x>\frac{1}{2}
\end{array}\right.
$$
(8) is:

The homogeneous general solution of the equation in Eq.

$$
\begin{aligned}
& w_{0}=e^{\delta x}\left(C_{1} \cos \delta x+C_{2} \sin \delta x\right)+ \\
& e^{-\delta x}\left(C_{3} \cos \delta x+C_{4} \sin \delta x\right)
\end{aligned}
$$

where, $\delta$ is the flexibility eigenvalue of the elastic foundation. $\delta=\sqrt[4]{k / 4 \mathrm{EI}}, C_{1}, C_{2}, C_{3}$, and $C_{4}$ are undetermined coefficients, respectively.

When $0 \leq x \leq l / 2$, the general solution can be deduced from the form on the right of the equation as follows:

$$
\begin{aligned}
& w_{1}=e^{\delta x}\left(C_{1} \cos \delta x+C_{2} \sin \delta x\right)+ \\
& e^{-\delta x}\left(C_{3} \cos \delta x+C_{4} \sin \delta x\right)+B_{1} \cos \theta x+B_{2}+\frac{\gamma h}{k}
\end{aligned}
$$

where, $B_{1}=k A /\left[4\left(k+16 \mathrm{EI} \pi^{4} / l^{4}\right)\right], B_{2}=A / 10, \quad \theta=2 \pi / l$.

According to the symmetry of the settlement curve,

$$
\left\{\begin{array}{l}
w_{1}^{\prime}=0 \\
w_{2}^{\prime \prime}=0
\end{array}\right.
$$

It can be obtained that $C_{1}=C_{2}, C_{3}=-C_{4}$, and Eq. (9) can be rewritten as:

$$
\begin{aligned}
& w_{1}=2 C_{1} \operatorname{ch} \delta x \cos \delta x+2 C_{2} \operatorname{sh} \delta x \sin \delta x \\
& +B_{1} \cos \theta x+B_{2}+\frac{\gamma h}{k}
\end{aligned}
$$

When $x \geq l / 2$, the general solution can be deduced from the form on the right of the equation as follows:

$$
\begin{aligned}
& w_{2}=e^{\delta x}\left(C_{1} \cos \delta x+C_{2} \sin \delta x\right)+ \\
& e^{-\delta x}\left(C_{3} \cos \delta x+C_{4} \sin \delta x\right)+\frac{\gamma h}{k}
\end{aligned}
$$

When $x \geq l / 2$, the subgrade is located in the nonsettlement zone of the foundation, the deflection of foundation beam $w_{2}=\gamma h / k$ at infinity. By substituting the 
above conditions into Eq. (11), the deflection expression of the foundation beam can be simplified as:

$$
w_{2}=e^{\delta x}\left(D_{1} \cos \delta x+D_{2} \sin \delta x\right)+\frac{\gamma h}{k}
$$

where, $D_{1}, D_{2}$ are undetermined coefficients.

The deflection of the beam on the elastic foundation when the uneven settlement occurs at the lower part can be expressed as

$$
w(x)=\left\{\begin{array}{l}
2 C_{1} \operatorname{ch} \delta x \cos \delta x+2 C_{2} \operatorname{sh} \delta x \sin \delta x+B_{1} \cos \theta x+B_{2}+\frac{\not h}{k}, 0 \leq x \leq \frac{1}{2} \\
e^{-\delta x}\left(D_{1} \cos \delta x+D_{2} \sin \delta x\right)+\frac{\not h}{k}, x>\frac{1}{2}
\end{array}\right.
$$

According to the continuity of deformation of foundation beam, it can be seen that:

$$
\left\{\begin{array}{l}
w_{1}(1 / 2)=w_{2}(1 / 2), w_{1}^{\prime}(1 / 2)=w_{2}^{\prime}{ }_{2}(1 / 2) \\
w^{\prime \prime}{ }_{1}(1 / 2)=w^{\prime \prime}{ }_{2}(1 / 2), w^{\prime \prime}{ }_{1}(1 / 2)=w^{\prime \prime}{ }_{2}(1 / 2)
\end{array}\right.
$$

For Eq. (13), in the actual solution, the values of $C_{1}$ and $C_{2}$ are usually very small, so the subgrade deformation w1 in the settlement is mainly controlled by the latter three items and still shows the cosine type.

\subsection{Subgrade inclination based on foundation beam theory}

When the uneven settlement of foundation is not symmetrical about the subgrade, the subgrade will produce inclined deformation. The inclined deformation of subgrade makes the original straight section turn into a curved section, which causes the height difference between railway tracks.

The centrifugal force higher than the train's own gravity is generated when the high-speed train passes by, which aggravates the change of driving momentum and causes the vehicle bump. In addition, the inclination of the subgrade will accelerate the destruction of the track system. When the degree of inclination of the subgrade is large, the center of gravity of the traveling vehicle will be shifted, and the train will be in danger of rolling over.

Since the inclination of the roadbed is often analyzed from the cross section, the foundation beam is not infinite long beam. In the short beam problem, since the influence of load has not disappeared at the beam end, constant $C_{1}$ and $C_{2}$ are still unknown, so it is not suitable to adopt the method in the previous section. The deflection and internal force of the foundation beam under asymmetric load should be calculated by using the initial parameter method, and the deflection expression of the loaded section is only one more deflection correction term $y_{\mathrm{x}}$ than that of the unloaded section,

$$
y_{x}=\frac{P}{4 \mathrm{EI} \delta^{3}} \operatorname{ch} \delta^{2}(x-z) \sin \delta^{2}(x-z)-\operatorname{sh} \delta^{2}(x-z) \cos \delta^{2}(x-z)
$$

where, $P$ is the concentrated force, and $z$ is the length of the no-load section.

When the displacement boundary condition is applied to the foundation surface, the settlement amplitude is located at the leftmost end of the foundation beam, where $O A$ corresponds to the loaded section, and $\mathrm{AB}$ is the unloaded section, as shown in Fig. 8. In the $A B$ section, $f(x)=0$, the basic differential equation is a homogeneous differential equation, and its deflection $y_{1}$ is obtained by Eq. (11), while $\theta, M$, and $Q$ can be obtained by differentiating $y$, then the deflection and internal force of the $\mathrm{AB}$ section are expressed as:

$$
\left\{\begin{array}{l}
y_{1}=e^{\delta x}\left(C_{1} \cos \delta x+C_{2} \sin \delta x\right)+e^{-\delta x}\left(C_{3} \cos \delta x+C_{4} \sin \delta x\right) \\
\theta=\delta\left\{e^{\delta x}\left[\left(C_{1}+C_{2}\right) \cos \delta x+\left(C_{1}-C_{2}\right) \sin \delta x\right]-e^{\delta x}\left[\left(C_{3}-C_{4}\right) \cos \delta x+\left(C_{3}+C_{4}\right) \sin \delta x\right]\right\} \\
M=-2 \mathrm{EI} \delta^{2}\left\{e^{\delta x}\left[C_{2} \cos \delta x-C_{1} \sin \delta x\right]-e^{-\delta x}\left[C_{4} \cos \delta x-C_{3} \sin \delta x\right]\right\} \\
Q=-2 \mathrm{EI} \delta^{2}\left\{e^{\delta x}\left[\left(C_{2}-C_{1}\right) \cos \delta x+\left(C_{2}+C_{1}\right) \sin \delta x\right]-e^{-\delta x}\left[\left(C_{4}+C_{3}\right) \cos \delta x-\left(C_{3}-C_{4}\right) \sin \delta x\right]\right\}
\end{array}\right.
$$

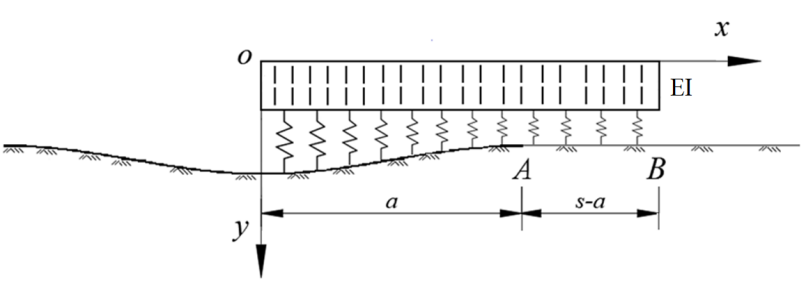

Fig. 8 Short beam model of uneven settlement subgrade.

In the initial parameter method, the above solutions need to be rewritten into the initial parameter form. Among them, the four integral constants $C_{1}, C_{2}, C_{3}$, and $C_{4}$ are represented by the four initial parameters of the endpoint, $y_{0}, \theta_{0}, M_{0}$, and $Q_{0}$, which can be obtained through conversion:

$$
\begin{aligned}
& y_{1}=y_{0} \operatorname{ch} \delta x \cos \delta x+\frac{\theta_{0}}{2 \delta}(\operatorname{sh} \delta x \cos \delta x+\operatorname{ch} \delta x \sin \delta x) \\
& -\frac{M_{0}}{2 \mathrm{EI} \delta^{2}} \operatorname{sh} \delta x \sin \delta x-\frac{Q}{4 \mathrm{EI} \delta^{3}}(\operatorname{ch} \delta x \sin \delta x-\operatorname{sh} \delta x \cos \delta x)
\end{aligned}
$$

For the $O A$ section, there is settlement deformation at the lower part. According to the Winkler's hypothesis, the relationship between the subsidence of foundation beam and the load is as follows:

$$
P(x)=k f(x)+\gamma h
$$

As shown in Fig. 10, the uneven settlement displacement boundary $f(\mathrm{x})$ is applied from $O$ to $A$,

$$
P(x)=\left\{\begin{array}{l}
k \frac{A}{2}\left(1-\cos \frac{2 \pi x}{l}+\gamma h\right), \quad 0<x<a \\
\gamma h, a<x
\end{array}\right.
$$

For the section $x \quad(0<x<a)$ in the $O A$ section, the distributed load is decomposed into multiple concentrated forces, and the correction term is solved according to the concentrated force. For this reason, the distance from the end point is $z$, take the micro-segment $\mathrm{d} z$, the load on the microsegment $\mathrm{d} P=P(x) \mathrm{d} z$, and the deflection correction value caused by the load $\mathrm{d} P$ at the section $z$ can be obtained from Eq. (14), 


$$
\begin{gathered}
y_{x}=\frac{1}{\mathrm{EI} \delta^{3}} \int_{0}^{x} P(x) \operatorname{ch} \delta^{2}(x-z) \sin \delta^{2}(x-z) \\
\left.2(x-z) \cos \delta^{2}(x-z)\right)
\end{gathered}
$$

Since the deflection value of $O A$ section differs from section $A B$ by only one deflection correction term, namely

$y_{2}=y_{1}+y_{x}$

The deflection value at any position on the subgrade can be obtained by Eqs. (16) and (20). In order to calculate the degree of inclination of the subgrade, the inclination coefficient $\tau$ is introduced:

$$
\tau=\frac{y_{0}-y_{\mathrm{c}}}{s}
$$

where, $y_{\mathrm{o}}$ is the deflection at point $O, y_{\mathrm{c}}$ is the deflection at any point on the foundation beam, and $s$ is the width of the subgrade.

\section{Results and Discussion}

Without considering the secondary activation of the minedout areas, the ground deformation of the mined-out areas is simplified as the stratum compression deformation caused by the additional stress on the ground and the residual deformation of the mined-out areas. According to the probability integral method and stress area method, combined with the geological survey report of Xincheng mined-out areas, the accumulated deformation of ground subsidence and foundation compression deformation under different subgrade heights was obtained, which were 63.52 $\mathrm{mm}, 115.02 \mathrm{~mm}, 166.97 \mathrm{~mm}$, and $198.26 \mathrm{~mm}$, respectively. In order to further analyze the influence of foundation settlement amplitude, the settlement range on subgrade deformation and the geometric mapping relationship with subgrade deformation. The basic calculation parameters of subgrade are selected as follows: $\mathrm{EI}=200 \mathrm{MN} / \mathrm{m}^{2}, k=50$ $\mathrm{MN} / \mathrm{m}^{2}, \gamma=20 \mathrm{kN} / \mathrm{m}^{2}$, the embankment width is $40 \mathrm{~m}$, and the train load is equivalent to $1 \mathrm{~m}$ high embankment. Among them, the settlement range is $20 \mathrm{~m}, 30 \mathrm{~m}, 40 \mathrm{~m}, 50 \mathrm{~m}$ and 60 $\mathrm{m}$, respectively.

\subsection{Mapping relationship between ground non-uniform} settlement and subgrade geometric deformation

The deformation characteristics of railway subgrade caused by uneven settlement of foundation are shown in Fig. 9. Under the action of cosine settlement curve, the geometric deformation of subgrade is also cosine-type. At the nonuniform settlement wavelength $S=40 \mathrm{~m}$, the variation trend of the subgrade settlement along with the settlement amplitude of the foundation is similar, and typical curve features are shown in Fig. 9(a). With the increase of the settlement amplitude of foundation, the increment of subgrade settlement gradually decreases. The settlement amplitude of foundation increases from $63.52 \mathrm{~mm}$ to 198.26 $\mathrm{mm}$, and the maximum settlement of subgrade increases from $16.3 \mathrm{~mm}$ to $34.7 \mathrm{~mm}$. When the non-uniform settlement amplitude $A=115.02 \mathrm{~m}$, the variation rule of subgrade settlement with the wavelength of foundation settlement curve is shown in Fig. 9(b). When the settlement wavelength is less than $20 \mathrm{~m}$, the subgrade settlement is less affected by the foundation settlement. When the settlement wavelength is expanded to $30 \mathrm{~m}$, the subgrade settlement increases nonlinearly with the increase of foundation settlement, and the most obvious increase is in the range of settlement wavelength $30-50 \mathrm{~m}$. As the compactness of subgrade soil in the settlement center increases gradually, when the settlement wavelength is extended to $50 \mathrm{~m}$, the increase of subgrade settlement decreases with the increase of settlement curve wavelength. Therefore, the settlement wavelength can alleviate the increase of settlement difference between superstructure and foundation.

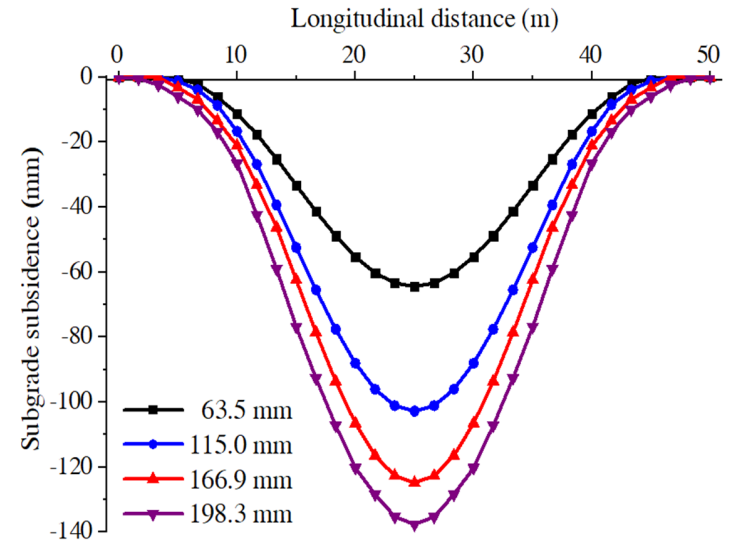

(a) Subgrade settlement

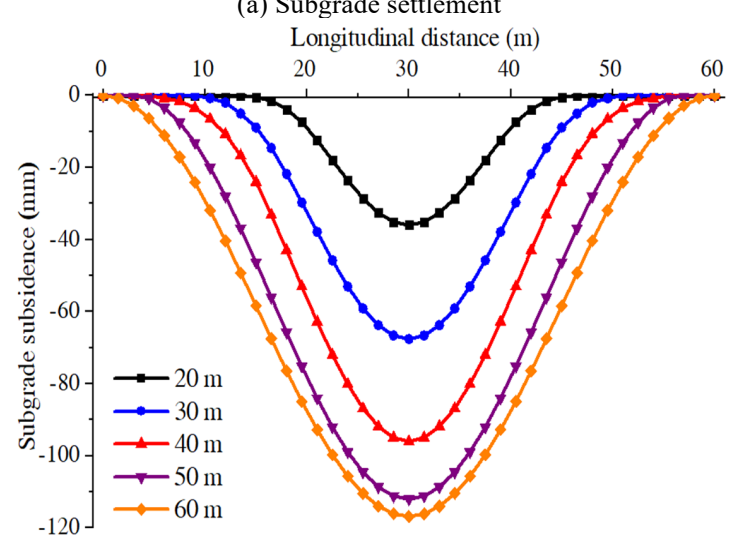

(b) subgrade inclined deformation

Fig. 9 Subgrade deformation with different settlement amplitude.

Based on the above mentioned discussion, both amplitude and wavelength of the uneven settlement have a positive correlation with the settlement of subgrade. The corresponding empirical equation can be expressed as

$$
Y=0.24 A+1.70 S-2.75 \times 10^{-4} A^{2}-0.01 S^{2}-45.61
$$

The Eq. (22) presents the relationship of settlement of subgrade $Y$ with settlement amplitude $A$ and wavelength $S$. The preceding empirical has a higher correlation coefficient at 0.984 , which shows good correlation among the three variables of settlement of subgrade, amplitude of the uneven settlement and wavelength. When the amplitude and wavelength of the uneven settlement change, the related settlement of subgrade may change immediately. The empirical equation obtained in this study can be further applied to the research field of the mapping relationship between the surface uneven settlement and the geometric deformation of subgrade.

\subsection{Subgrade inclination variation with foundation settlement}

The inclined deformation characteristics of railway subgrade caused by uneven settlement are shown in Fig. 10. At the non-uniform settlement wavelength $S=40 \mathrm{~m}$, the curve 
change trend of the inclined deformation of the subgrade with the non-uniform settlement amplitude is similar as shown in Fig. 10(a). With the increase of the settlement amplitude of foundation, the increment of subgrade settlement gradually decreases. The settlement amplitude of foundation increases from $63.52 \mathrm{~mm}$ to $198.26 \mathrm{~mm}$, and the maximum settlement of subgrade increases from $16.3 \mathrm{~mm}$ to $34.7 \mathrm{~mm}$.

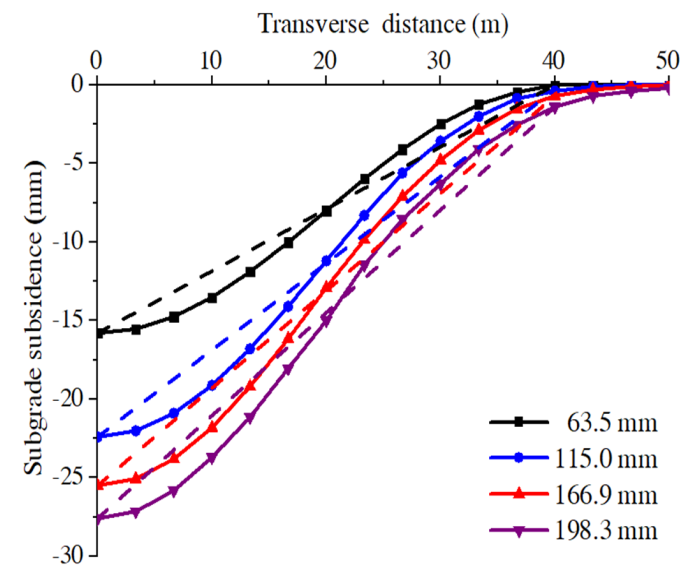

(a) Subgrade settlement

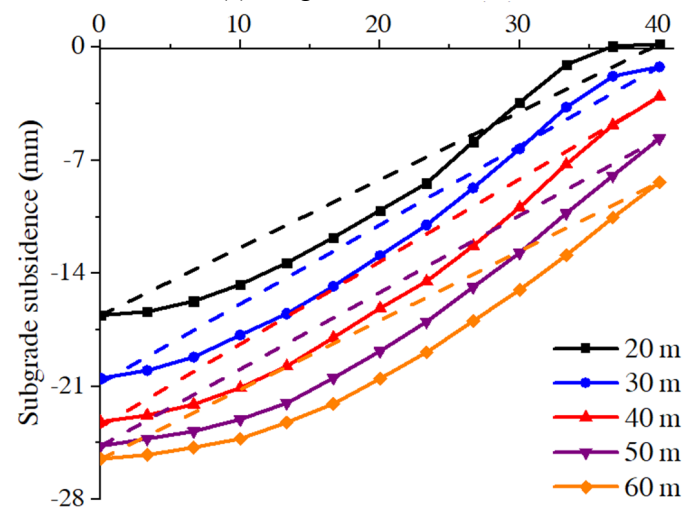

(b) subgrade inclined deformation

Fig. 10 Subgrade deformation with different settlement wavelength.

As shown in Fig. 10(b), when $l / 2$ is less than the width of the subgrade, only the left half of the subgrade is in the foundation settlement area. Due to the large bending rigidity of the pavement, the right edge of the subgrade surface appears local camber, and the subgrade inclination is small at this time. When $l / 2$ is larger than the width of subgrade, the subgrade is inclined deformation, accompanied by the overall subsidence, and shows a good following quality. The wavelength of settlement curve increases from $30 \mathrm{~m}$ to $60 \mathrm{~m}$ at equal intervals, and the inclination coefficient of the subgrade first increases and then decreases. When the half wave length of settlement curve is equal to the width of subgrade, the slope coefficient reaches the peak value of $0.619 \mathrm{~mm} / \mathrm{m}$. As the compactness of subgrade soil increases gradually, the slope coefficient is not symmetrically distributed along the $l / 2$ equal to the width of subgrade, but shows the change characteristics of increases rapidly and then decreases slowly. Similar to the subgrade settlement, the inclination of subgrade is also affected by two independent variables, namely amplitude and wavelength of the uneven settlement. The relationship of inclination coefficient of the subgrade to amplitude and wavelength of the uneven settlement can be expressed as,

$$
\begin{aligned}
& \tau=0.002 A+0.014 S-2.402 \times 10^{-6} A^{2} \\
& -1.843 \times 10^{-4} S^{2}+1.041 \times 10^{-5} A S-0.010
\end{aligned}
$$

The correlation coefficient of the preceding fitting bivariate polynomial is 0.980 . The amplitude of the uneven settlement has a positive correlation with the subgrade inclination coefficient, and the influence of the settlement amplitude on the subgrade inclination is more obvious than that of the wavelength.

\section{Conclusions}

Taking the Taijiao high-speed railway above the Xincheng mined-out areas as the research background, the probability integral method and the stress area method were used to improve the evaluation criteria of the foundation suitability of the high-speed railway, and the calculation of the subgrade deformation was analyzed based on the elastic foundation beam theory. The main conclusions are as follows:

(1) Based on the general judgment standard of the groud loading influence depth $\left(\sigma_{\mathrm{z}}=0.10 \sigma_{\mathrm{cz}}\right)$, an accurate and suitable criterion for evaluating the foundation adaptability of high-speed railway is proposed, and the amplification factor is introduced, which can be used as a reference value for the design of foundation engineering above the minedout areas.

(2) The model of foundation beam with symmetrical and asymmetrical distributed displacement boundary is established. The deflection differential equation of pavement slab is derived. The inclination coefficient is introduced to comprehensively characterize the degree of subgrade inclination. The deformation of subgrade caused by uneven settlement is significantly affected by settlement wavelength and amplitude.

(3) When the settlement wavelength exceeds the width of subgrade, the increase becomes slow and tends to be stable. When the half wave length of settlement curve is equal to the width of subgrade, the inclination coefficient will reach the peak value. The empirical equations for the subgrade settlement amount and inclination coefficient variation with settlement amplitude and wavelength are proposed, which can be used to predict the subgrade deformation caused by uneven settlement of the foundation.

This study mainly focused on the foundation adaptability and subgrade deformation analysis of high-speed railway above the mined-out areas, and some meaningful conclusions were obtained. To ensure the safety of highspeed railway crossing the mined-out areas, in the next step, the similar model experiments will be carried out to provide the technical basis.

\section{Acknowledgements}

This work was financially supported by the National Natural Science Foundation of China (51774112; U1810203), and the Fundamental Research Funds for the Universities of Henan Province (NSFRF200202), China.

This is an Open Access article distributed under the terms of the Creative Commons Attribution License. 


\section{References}

1. Solonenko, I., "The equipment for determining the impact of traffic environment on road pavement". Technical Journal, 13(2), 2019, pp. 149-153.

2. Wang, S. R., Shi, K. P., Li, Z. H., Li, Z. C., Wang, Y. F., "Spatial distribution law of vibration acceleration of ultra-small-spacing tunnel under train moving loads". Journal of Engineering Science and Technology Review, 12(6), 2019, pp. 96-104.

3. Luo, T., Wang, S. R., Zhang, C. G., Liu, X. L., "Parameters deterioration rules of surrounding rock for deep tunnel excavation based on unloading effect". Dyna, 92(6), 2017, pp. 648-654.

4. Wang, S. R., He, S. N., Li, C. Y., Yan, W. F., Zou, Z. S., "Near-fault mining induced microseismic distribution characteristics and its influencing factors". Tehnicki Vjesnik-Technical Gazette, 24(2), 2017, pp. 535-542.

5. Helm, P. R., Davie, C. T., Glendinning, S. "Numerical modelling of shallow abandoned mine working subsidence affecting transport infrastructure". Engineering Geology, 154, 2013, pp. 6-19.

6. Zhao, Y. H., Wang, S. R., Zou Y. F., Wang, X. C., Huang, B. Q., Zhang, X. G., "Pressure-arching characteristics of fractured strata structure during shallow horizontal coal mining". Tehnicki VjesnikTechnical Gazette, 25(5), 2018, pp. 1457-1466.

7. Wang, S. R., Li, N., Li, C. L., Zou, Z. S., Chang, X., "Instability mechanism analysis of pressure-arch in coal mining field under different seam dip angles". Dyna, 90(3), 2015, pp. 279-284.

8. Wang, S. R., Shi, K. P., He, Y. S., Wang, X. Q., "Dynamic response analysis of middle pillar for ultra-small spacing tunnels under train vibration loads". Journal of Engineering Science and Technology Review, 2019, 12(3): 30-37.

9. Srivastava, S., Pal, S. K., Kumar, R., "A time-lapse study using selfpotential and electrical resistivity tomography methods for mapping of old mine working across railway-tracks in a part of Raniganj coalfield, India”. Environmental Earth Science, 79(13), 2020, pp. 113.

10. Zhang, J. Y., Cai M. F., Zhang, Q., "Distribution laws of ground stress after newly increased load on surface above mined-out areas". Chinese Journal of Geotechnical Engineering, 32(7), 2010, pp. 10961100.

11. Ren, L. W, Zhou, G. L., Dun, Z. L., "Case study on suitability and settlement of foundation in goaf site". Rock and Soil Mechanics, 39(8), 2018, pp. 2922-2932.

12. Diaz-Fernandez, M. E., Alvarez-Fernandez, M. I., Alvarez-Vigil, A. E., "Computation of influence functions for automatic mining subsidence prediction”. Computational Geosciences, 14(1), 2010, pp. 83-103.

13. Xu. P., Mao, X. B., Zhang, M. X., "Analysis of the deformation zone and its characteristics of the building foundations in mininginduced subsidence area". Journal of Mining \& Safety Engineering, 31(4), 2014, pp. 624-630.

14. Ng, A. H. M., Ge, L. L., Du, Z. Y. Wang, S. R., Ma, C., "Satellite radar interferometry for monitoring subsidence induced by longwall mining activity with Radarsat-2, Sentinel-1 and ALOS-2 data". International Journal of Applied Earth Observation and Geoinformation, 61, 2017, pp. 92-103.

15. Maria, P., Gerardo, H., Marek, G., "Combination of conventional and advanced DInSAR to monitor very fast mining subsidence with TerraSAR-X data: Bytom city (Poland)". Remote Sensing, 7(5), 2015, pp. 5300-5328.
16. Soeung, S., Lee, SH., Lee, S. J., "Causing factors of additional settlement in high-speed railways in Korea". KSCE Journal of Civil Engineering, 22(10), 2018, pp. 3843-3851.

17. Phadke, H. D., Jaiswal, O. R., "Dynamic response of railway track resting on variable foundation using finite element method". Arabian Journal for Science and Engineering, 45(6), 2020, pp. 4823-4841.

18. Ključanin, D., Manđuka, A., "The cantilever beams analysis by the means of the first-order shear deformation and the Euler-Bernoulli theory". Technical Journal, 13(1), 2019, pp. 63-67.

19. Rodrigues, C.; Simões, F. M. F., Pinto da Costa, A., Froio, D., Rizzi, E., "Finite element dynamic analysis of beams on nonlinear elastic foundations under a moving oscillator". European Journal of Mechanics a-Solids, 68, 2018, pp. 9-24.

20. Castro Jorge, P., Simões, F. M. F., Pinto da Costa, A., "Dynamics of beams on non-uniform nonlinear foundations subjected to moving loads". Computer \& Structures, 148, 2015, pp. 26-34.

21. Khan, M. A., Wang, J. X., Sarker, D., "Development of analytic method for computing expansive soil-Induced stresses in highway pavement". International Journal of Geomechanics, 20(2), 2020, pp. $1-14$.

22. Neto, J. O. A., "Application of the two-layer system theory to calculate the settlements and vertical stress propagation in soil reinforcement with geocell". Geotextiles and Geomembranes, 47(1), 2019, pp. 32-41.

23. Zhang, L., Cheng, Q. G., Zhao, M. H. "Deformation calculation of geocell reinforcement based on the double Euler beams theory". Journal of Hunan University (Natural Sciences), 44(9), 2017, pp. 114-121.

24. He, W., Zuo, S. H., Bai, X. H., "Mechanical analysis of concrete pavement via the theory of double layerbeams on elastic foundation". Chinese Journal of Applied Mechanics, 37(1), 2020, pp. 63-69.

25. Guo, Y., Zhai, W. M., "Long-term prediction of track geometry degradation in high-speed vehicle-ballastless track system due to differential subgrade settlement". Soil Dynamics and Earthquake Engineering, 113, 2018, pp. 1-11.

26. Zhou, W. B., Nie, L. X., Jiang, L. Z., "Mapping relation between pier settlement and rail deformation of unit slab track system". Structures, 27, 2020, pp. 1066-1074.

27. Jiang, H. G., Li, X. L., Xin, G. F., "Geometry mapping and additional stresses of ballastless track structure caused by subgrade differential settlement under self-weight loads in high-speed railways". Transportation Geotechnics, 18, 2018, pp. 103-110.

28. Zhang, C. L., Jiang, G. L., "Full-scale model testing of the dynamic response of lime-stabilized weathered red mudstone subgrade under railway excitation". Soil Dynamics and Earthquake Engineering, 130, 2020, pp. 1-11.

29. Guan, F. J., "Line selection and survey evaluation of multidimensional space-time goaf of Taiyuan-Jiaozuo railway". Journal of Railway Engineering Society, 37(2), 2020, pp. 11-16.

30. Liu, X., Wang, J., Guo, J., "Time function of surface subsidence based on Harris model in mined-out area". International Journal of Mining Science and Technology, 23(2), 2013, pp. 245-248. 